\title{
CNS Medications as Predictors of Precipitous Cognitive Decline in the Cognitively Disabled Aged: A Longitudinal Population-Based Study
}

\author{
Juha Puustinen $^{\mathrm{a}, \mathrm{d}-\mathrm{f}} \quad$ Janne Nurminen ${ }^{\mathrm{a}, \mathrm{c}, \mathrm{d}, \mathrm{f}}$ Tero Vahlberg $^{\mathrm{b}}$ \\ Alan Lyles ${ }^{g, h}$ Raimo Isoaho ${ }^{a, d}$ Ismo Räihä ${ }^{a, d} \quad$ Sirkka-Liisa Kiveläa, d, g \\ Departments of a Family Medicine and ${ }^{b}$ Biostatistics, University of Turku, ${ }^{\mathrm{c}}$ Turku Health Centre, \\ ${ }^{\mathrm{d}}$ Department of Primary Health Care, Turku University Hospital and Satakunta Central Hospital, \\ Hospital Districts of Southwest Finland and Satakunta, Turku and Pori, eUnit of Geriatrics, \\ Satakunta Central Hospital, Pori, ${ }^{f}$ Härkätie Health Centre, Lieto, and ${ }^{9}$ Division of Social Pharmacy, \\ University of Helsinki, Helsinki, Finland; ${ }^{h}$ College of Public Affairs, School of Health and Human \\ Services, University of Baltimore, Baltimore, Md., USA
}

\section{Key Words}

Aged $\cdot$ CNS agents - Benzodiazepines - Parasympatholytics - Cholinergic antagonists • Memory disorders $\cdot$ Delirium disorders $\cdot$ Dementia disorders $\cdot$ Amnestic disorders • Cognitive disorders

\begin{abstract}
Background/Aims: Psychotropics and antiepileptics (AE) are medications commonly used among the aged with cognitive decline or dementia, although they may precipitate further cognitive decline. Our aim was to analyze the relationships between the use of (i) psychotropics (i.e. benzodiazepines or related drugs, BZD, antipsychotics, AP, or antidepressants, AD), opioids $(\mathrm{Op})$, anticholinergics (ACh) or AEs or the concomitant use of two of these drugs, and (ii) the risk of precipitous cognitive decline in an older ( $\geq 65$ years) cognitively disabled population. Methods: A longitudinal population-based study of general aged community-dwelling patients was executed in two phases (1990-1991 and 1998-1999) in Lieto, Finland. Fifty-two individuals cognitively disabled (MMSE score 0-23) at the 1990-1991 baseline form this study's sample. Cognitive abilities were assessed in each phase with the Mini-Mental State Examination (MMSE) and medication utilization data were collected in both phases. The mean follow-up time was 7.6 years. Multivariate models were used to analyze the change in MMSE total score between medication users and non-users. Results: BZD or any psychotropic use was associated with greater cognitive decline in elders aged $\geq 75$ years compared to non-users (change in MMSE sum score: $-8.6 \pm 7.0$ vs. $-3.3 \pm 5.6$ and $-5.9 \pm 7.0$ vs. $-2.7 \pm 6.4$, respectively). A greater decline was also
\end{abstract}


associated specifically with the concomitant use of BZD and AP (-16 vs. $-1.4 \pm 7.8$ ); as were BZD and any drug with CNS effects ( $-9.6 \pm 9.9$ vs. $-1.3 \pm 7.2)$ compared to non-users. The concomitant use of BZD and AD (-10.7 \pm 4.7 vs. $-3.2 \pm 5.6)$ or ACh $(-15.0 \pm 8.5$ vs. $-3.3 \pm 5.6)$ or any drug with CNS effects $(-13.3 \pm 6.5$ vs. $-3.3 \pm 5.6)$ was associated with cognitive decline in patients $\geq 75$ years compared to non-users of any drug with CNS effects. Conclusion: The use of a BZD or any psychotropic medication may be an independent risk factor for cognitive decline in the cognitively disabled aged, and patients co-prescribed psychotropic medications had greater cognitive decline. Studies with larger sample sizes and studies on possible pathophysiologic mechanisms are needed.

Copyright $\odot 2012$ S. Karger AG, Basel

\section{Introduction}

Psychotropics [1-4] and antiepileptic medications [5-7] are commonly used to treat the behavioral and psychological symptoms of dementia [8]. A concern, however, has arisen as to whether these medications may lead to a precipitous cognitive deterioration among patients with pre-existing cognitive decline or dementing diseases.

Conventional antipsychotics (AP) can cause anticholinergic and extrapyramidal adverse effects in the aged [9]. A randomized, placebo-controlled trial failed to show a positive benefit/risk ratio for the use of APs among home-dwelling elders with Alzheimer's disease [10]. Some longitudinal epidemiologic studies $[11,12]$ and randomized controlled trials $[13,14]$ have shown that AP use is related to a precipitous cognitive decline among patients with dementing diseases. This relationship has not been reported in other longitudinal epidemiologic studies [15-18] or short-term treatment studies [10, 19-21].

There is some evidence of an association between the use of medications other than APs which have CNS effects and cognitive decline. Benzodiazepines or related drugs (BZD) may worsen cognition in patients with Alzheimer's disease, especially when combined with APs [12]. Antidepressants (AD) with anticholinergic properties (especially tricyclic ADs) are cognitively toxic to aged patients while patients may tolerate non-anticholinergic selective serotonin re-uptake inhibitors (SSRIs) [22]. The adverse effects of anticholinergic medications (AChs) have been extensively documented in both non-demented and demented populations $[23,24]$. Community-dwelling individuals using AChs are five times more likely to be classified as cognitively impaired compared to non-users; however, no excess risk of developing dementia was detected [25].

Due to a lack of evidence and contradictory trial results [26], a systematic review did not recommend routine use of antiepileptics (AE) in treating the behavioral and psychological symptoms of dementia [8]. Our literature search did not identify any studies on the use of opioids (Op) and modified risk of cognitive deterioration in cognitively disabled patients, nor have Op therapies for chronic pain among patients with dementia been studied [27].

The analyses in the studies above, with the exception of one study [12], only consider the use of a single drug type. Consequently, the adverse effects of concomitant use of drugs with CNS effects on patients with pre-existing cognitive decline have not been explored. However, concomitant use of several kinds of drugs with CNS effects is common in pharmacotherapy for older patients [28], especially among those with dementia [29]. In a longitudinal study conducted in cognitively intact aged, the concomitant use of Ops and BZDs or Ops and any type of CNS medication was associated with the cognitive decline compared to nonusers of these medications [30]. It can be hypothesized that the concomitant use of psychotropics or other drugs with CNS effects may have stronger negative effects on cognitive function than the use of a single drug with such effects. 
The aim of the present study was to describe and analyze the relationships between the use of a psychotropic (i.e. BZD, AP or AD), opioid, anticholinergic or antiepileptic drug or the concomitant use of two of these drugs, and the risk of precipitous cognitive decline in a population aged $\geq 65$ years with deteriorated cognitive functioning at baseline.

\section{Methods}

\section{Participants and Data Collection}

This study was part of a longitudinal population-based study performed in the municipality of Lieto, South-Western Finland [31,32]. The first phase of the Lieto study was carried out between October 1, 1990 and December 31, 1991, and the second phase between March 1, 1998 and September 31, 1999.

The population of the first phase consisted of residents who were born in 1926 or earlier ( $n=1,283)$. Of these, 1,196 (93\%, 488 men and 708 women) participated. The population of the second phase consisted of residents born in 1933 or earlier $(n=1,533)$ of whom 1,260 (82\%) participated. The validated Finnish version of the Mini-Mental State Examination (MMSE) [33] was administered to all participants. Its scale consists of 23 items, and the sum score ranges from 0 to 30 , with higher scores indicating better cognitive performance.

The population for the present longitudinal study was formed from those (i) who participated in the first phase and had a total score of 0-23 on the MMSE [34], indicating deteriorated cognitive functioning, and (ii) who were alive and participated in the second phase. The realized sample of the study population consisted of 52 residents (17 men and 35 women); the mean follow-up time was $7.6 \pm 0.5$ years (range: 6.6-8.7 years).

During both phases, proxies (relatives or caregivers) of the participants were interviewed for information on the participants' socioeconomic background, physical and psychosocial factors and functional abilities, their use of drugs and health behavior(s). Participants were clinically examined by a health center physician belonging to the research team (R.I. or M.L.), and clinical tests were performed. Medical records in the Härkätie Health Centre, Lieto, were used to record previously diagnosed diseases. Similar processes were performed in both phases. Cognitive abilities were measured by a trained nurse using the MMSE [34] in both study phases. Information about medication use was collected in the proxy interviews. Subjects and their proxies had been requested to bring all of their prescription forms and drugs with them so that actual medication use could be confirmed. All regularly or irregularly taken prescription drugs and non-prescribed drugs (e.g. vitamins) taken during the seven days prior to the interview were recorded.

Drugs were defined by using the Anatomical Therapeutic Chemical (ATC) Classification [35]. The groups of drugs defined as having a CNS effect and therefore included in the analyses were: Ops (ATC codes N01AH, N02A, N02BE51, R05DA, R05FA), AChs (ATC codes N04A, N05AA01, N05AA02, N05AB01, N05AB02, N05AB03, N05AB04, N05AC01, N05AC02, N05AF01, N05AF03, N05AF05, N05BB01, N06AA04, N06AA06, N06AA09, N06AA12, 102AG, A03AA, A03AB, A03AX03, A03B, A03CA, A03CB31, A03DA, A03FA01, A04AD01, A04AD12, C01BA01, C01BA03, C01BA51, C01BA71, R03BB, M03B, G04BD, S01FA, R01BA01, R01BA51, R06AB01, R06AE03, R06AE53), AEs (ATC code N03A), BZDs (ATC codes N05BA, N05CD, N03AE01, N05CF, A03CA, C01DA70, M05AA51, N06CA01, N02BA71), APs (ATC codes N05A, N06CA01), and ADs (ATC code N06A, N06CA).

In both study phases, informed consent was obtained from every participant's relative or formal caregiver. Plans for both the first and second Lieto studies were approved by the Joint Ethics Committee of the University of Turku and Turku University Central Hospital. 
Statistical Analyses

Statistical analyses were performed on the total population and separately by gender and age group (younger age group: 65-74 years; older age group: $\geq 75$ years). Participants using a CNS medication at the beginning of the follow-up were compared (i) with participants who did not use any of these medications at baseline and (ii) with participants not using that specific medication. Participants using a combination of two or more of the CNS medications were compared with participants using none of the individual CNS medications or their combinations.

$\chi^{2}$ and Fisher's exact tests were used to test differences between genders and age groups, and between medication users and control groups at baseline and during the follow-up examination. The statistical significance of differences in the use of medications between baseline and follow-up examination was analyzed with McNemar's test for every group of medications. The significance of changes in MMSE total scores during the follow-up in the total population and in all subgroups was tested with the Wilcoxon signed rank test. Differences between mean MMSE total scores and the changes of mean MMSE total scores between the groups were tested with the Mann-Whitney U test. Associations between the use of a specific group of CNS medications or the use of a combination of CNS medications and the risk of cognitive decline were analyzed by the Mann-Whitney U test. Significance of differences in cognitive functioning changes during the follow-up between the users of a certain group of CNS medications or the users of a combination of CNS medications and the corresponding control group of non-users was tested with the Mann-Whitney U test. As these are nonparametric tests, our analyses conservatively estimate realized $\mathrm{p}$ values.

After these analyses, adjusted analyses using analysis of covariance were performed for those groups in which the associations between the use of a certain CNS medication or the concomitant use of certain CNS medications and the risk for cognitive decline were either significant $(\mathrm{p}<0.05)$ or tending toward significant $(0.05<\mathrm{p}<0.10)$ in the bivariate analyses. Associations between probable confounding variables (age, sex, education, hypertension, atrial fibrillation or flutter, diabetes mellitus, congestive heart disease and smoking at baseline) and the decline in MMSE total scores were analyzed in the total population. From these variables, higher age $(p=0.0007)$ was associated with a statistically significant decline in MMSE total scores. Thus, only this variable was controlled as a confounding variable in the analyses of covariance.

\section{Results}

\section{Background Data}

Altogether 52 individuals participated in both phases of the study. Their MMSE total scores at baseline ranged from 0 to 23 (indicating deteriorated cognitive functioning). Fifteen (29\%) were men and $37(71 \%)$ women. The majority $(n=30 ; 58 \%)$ were $\geq 75$ years at the beginning of the follow-up, and 22 (42\%) were 65-74 years old. The mean age \pm SD was 75.9 \pm 7.2 years (range: $64-92$ ).

Altogether 15 participants (29\%) lived at home with other people, 33 (63\%) lived alone, and $4(8 \%)$ were institutionalized. Thirty-nine $(76 \%)$ were able to walk independently, 10 (20\%) with an assistive device, and $2(4 \%)$ with the help of another person. The mean number $\pm \mathrm{SD}$ of prescribed medications used regularly was $2.8 \pm 2.4$, and that of drugs used irregularly (as needed) was $0.8 \pm 1.1$. 
Table 1. Single and concomitant use of drugs with CNS effects at baseline, at follow-up examination and at both times in a population aged $\geq 65$ years with an MMSE total score of $0-23$

\begin{tabular}{|c|c|c|c|c|c|c|}
\hline & \multicolumn{2}{|c|}{$\begin{array}{l}\text { Baseline } \\
(\mathrm{n}=52)\end{array}$} & \multicolumn{2}{|c|}{$\begin{array}{l}\text { Follow-up } \\
(\mathrm{n}=52)\end{array}$} & \multicolumn{2}{|c|}{$\begin{array}{l}\text { Both at baseline and } \\
\text { follow-up }(n=52)\end{array}$} \\
\hline & $\mathrm{n}$ & $\%$ & $\mathrm{n}$ & $\%$ & $\mathrm{n}$ & $\%$ \\
\hline Ops & 6 & 12 & 6 & 12 & 2 & 4 \\
\hline AChs & 12 & 23 & 14 & 27 & 8 & 15 \\
\hline APs & 6 & 12 & 8 & 15 & 4 & 8 \\
\hline ADs & 5 & 10 & 9 & 17 & 4 & 8 \\
\hline BZDs & 11 & 21 & 15 & 29 & 7 & 13 \\
\hline AEs & 1 & 2 & 2 & 4 & 1 & 2 \\
\hline At least one of the above drugs & 24 & 46 & 29 & 56 & 8 & 15 \\
\hline
\end{tabular}

Use of Drugs at Baseline and during Follow-Up Examination

At baseline, BZDs and AChs were used by approximately every fifth participant (table 1). APs, ADs and Ops were used by every tenth participant. Half of the participants used at least one drug with effects on the CNS. No differences in the use of these drugs were found between men and women. Opioid use was more common among the older age group (20\%) than among the younger one $(0 \%)(\mathrm{p}=0.0328)$. Similarly, the use of at least one drug with effects on the CNS was more common among the older age group (63\%) than among the younger one $(23 \%)(\mathrm{p}=0.0051)$. The use of $\mathrm{AD}$ tended to be more common among the older age group than among the younger one but the difference did not achieve statistical significance. The use of these drugs did not change significantly from baseline during the followup. Ten to seventeen percent of the participants received concomitantly at least two drugs with effects on the CNS (table 2).

Cognitive Abilities at Baseline and Change by the Time of Follow-Up

Cognitive functioning tended to decline in the total population and in all subgroups during the follow-up period, but the change was statistically significant only in the older age group (table 3).

\section{Background Data and the Use of CNS Medications}

Users of CNS medications used more medications overall than did non-users, but the demographics between the two groups were similar (table 4).

\section{Use of a Single Drug with CNS Effects as a Predictor of Cognitive Decline}

After adjusting for confounding variables (age), the use of BZD or any psychotropic drug was still associated with the risk of cognitive decline in older ( $\geq 75$ years) patients (table 5 ).

\section{Concomitant Use of Two or More Drugs as a Predictor of Cognitive Decline}

After adjusting for the confounding variable (age), concomitant use of BZD with AP or any drug with CNS effects was still associated with cognitive decline in the total population.

Concomitant use of BZD and AD or ACh or any drug with CNS effects was associated with cognitive decline in the older population. These associations remained statistically significant after adjusting for the confounding variable (age). 
Table 2. Concomitant use of drugs with CNS effects by drug combinations in a population aged $\geq 65$ years at baseline with pre-existing cognitive decline (MMSE score 0-23)
Table 3. Cognitive functioning measured by MMSE at baseline and at a 7.6-year follow-up, by gender and age

\begin{tabular}{llc}
\hline Combinations of medications & $\mathrm{n}($ total = 52) & $\%$ \\
\hline Op and & 2 & 4 \\
ACh & 0 & 0 \\
AE & 1 & 2 \\
BZD & 2 & 4 \\
AP & 2 & 3 \\
AD & 4 & 8 \\
Any of the above drugs & & \\
ACh and & 0 & 0 \\
AE & 3 & 6 \\
BZD & 4 & 8 \\
AP & 2 & 3 \\
AD & 9 & 17 \\
Any of the above drugs & & \\
AE and & 0 & 0 \\
AD & 0 & 0 \\
BZD & 0 & 0 \\
AP & 0 & 0 \\
Any of the above drugs & & \\
BZD and & 1 & 10 \\
AP & 3 & \\
AD & 5 & \\
Any of the above drugs & 2 & \\
AP and & 5 & \\
AD & & \\
Any of the above drugs & & \\
AD and & & \\
Any of the above drugs & & \\
\hline
\end{tabular}

\begin{tabular}{llll}
\hline Population & \multicolumn{2}{l}{ MMSE sum score } & p value* \\
\cline { 2 - 3 } & $\begin{array}{l}\text { at baseline } \\
(1990-1991)\end{array}$ & $\begin{array}{l}\text { during follow-up } \\
(1998-1999)\end{array}$ & \\
\hline Total population & $20.0 \pm 5.5$ & $17.9 \pm 8.8$ & 0.129 \\
Men & $19.3 \pm 6.3$ & $15.7 \pm 7.5$ & 0.102 \\
Women & $20.4 \pm 5.2$ & $18.8 \pm 9.2$ & 0.406 \\
At baseline 65-74 years & $21.9 \pm 2.4$ & $22.3 \pm 7.8$ & 0.341 \\
At baseline $\geq 75$ years & $18.7 \pm 6.6$ & $14.7 \pm 8.2$ & 0.003 \\
\hline
\end{tabular}

Values denote means $\pm \mathrm{SD} .{ }^{*}$ Wilcoxon signed rank test.

\section{Discussion}

To our knowledge, this is the first longitudinal, population-based study describing and analyzing associations between concomitant use of drugs with effects on the CNS and the long-term risk of cognitive decline among cognitively disabled aged individuals.

We were able to show the association between use of any psychotropic drug and the risk of cognitive decline in a general population with pre-existing cognitive decline. We could also replicate the finding that BZD use predicts precipitous cognitive decline in a population 
Table 4. Background data on the use of medications with CNS effects and significance of the differences between users of these drugs and non-users at baseline

\begin{tabular}{|c|c|c|c|}
\hline Background variable & $\begin{array}{l}\text { Users } \\
(\mathrm{n}=24)\end{array}$ & $\begin{array}{l}\text { Non-users } \\
(\mathrm{n}=28)\end{array}$ & $\mathrm{p}$ value \\
\hline Age, years & $77.8 \pm 6.6$ & $74.4 \pm 7.5$ & $0.114^{*}$ \\
\hline Number of all medications & $5.4 \pm 3.2$ & $2.1 \pm 2.1$ & $<0.001^{*}$ \\
\hline Number of regularly taken medications & $4.2 \pm 2.4$ & $1.7 \pm 1.6$ & $<0.001^{*}$ \\
\hline Number of medications taken as needed & $1.2 \pm 1.4$ & $0.4 \pm 0.7$ & $0.016^{*}$ \\
\hline Number of all medications excluding CNS medications & $3.9 \pm 2.9$ & $2.1 \pm 2.1$ & $0.021^{*}$ \\
\hline Number of regularly taken medications excluding CNS medications & $3.1 \pm 2.2$ & $1.7 \pm 1.6$ & $0.017^{*}$ \\
\hline Number of medications taken as needed excluding CNS medications & $0.8 \pm 1.2$ & $0.4 \pm 0.7$ & $0.262^{*}$ \\
\hline Females & $5(21)$ & $10(36)$ & $0.238^{* *}$ \\
\hline \multicolumn{4}{|l|}{ Marital status } \\
\hline Married & $4(17)$ & $5(18)$ & \multirow{3}{*}{$0.250^{* *}$} \\
\hline Unmarried or divorced & $8(33)$ & $15(54)$ & \\
\hline Widowed & $12(50)$ & $8(29)$ & \\
\hline \multicolumn{4}{|l|}{ Place of living } \\
\hline At home alone & $7(29)$ & $8(29)$ & \multirow{3}{*}{$0.077^{* *}$} \\
\hline At home with other person & $13(54)$ & $20(71)$ & \\
\hline In institution or nursing home & $4(17)$ & $0(0)$ & \\
\hline \multicolumn{4}{|l|}{ Education } \\
\hline Less than basic & $7(29)$ & $8(29)$ & \multirow{3}{*}{$0.870^{* *}$} \\
\hline Basic & $8(67)$ & $20(71)$ & \\
\hline More than basic & $1(4)$ & $0(0)$ & \\
\hline \multicolumn{4}{|l|}{ Ability to walk } \\
\hline Independently & $15(65)$ & $24(86)$ & \multirow{3}{*}{$0.119^{* *}$} \\
\hline With assistive device & $6(26)$ & $4(14)$ & \\
\hline With help of another person & $2(9)$ & $0(0)$ & \\
\hline \multicolumn{4}{|l|}{ Diagnosed diseases } \\
\hline Depression & $5(21)$ & $1(4)$ & $0.084^{* *}$ \\
\hline Alcohol-related disease & $0(0)$ & $1(4)$ & $1.000^{* *}$ \\
\hline Hypertension & $10(42)$ & $10(36)$ & $0.660^{* *}$ \\
\hline Hypercholesterolemia & $0(0)$ & $3(11)$ & $0.240^{* *}$ \\
\hline Diabetes mellitus (type I or II) & $5(21)$ & $2(7)$ & $0.227^{* *}$ \\
\hline TIA & $4(17)$ & $2(7)$ & $0.397^{* *}$ \\
\hline Cerebral infarct & $1(4)$ & $0(0)$ & $0.462^{* *}$ \\
\hline Cerebral hemorrhage & $1(4)$ & $0(0)$ & $0.462^{* *}$ \\
\hline Cerebral trauma & $0(0)$ & $1(4)$ & $1.000^{* *}$ \\
\hline Malignant tumor or cancer & $1(4)$ & $0(0)$ & $0.462^{* *}$ \\
\hline HIV, lues or borreliosis & $0(0)$ & $0(0)$ & $1.000^{* *}$ \\
\hline Dementia (all types) & $1(4)$ & $0(0)$ & $0.462^{* *}$ \\
\hline
\end{tabular}

Values denote means $\pm \mathrm{SD}$ or numbers with percentages in parentheses.

${ }^{*}$ Mann-Whitney U test. ${ }^{* *} \chi^{2}$ test or Fisher's exact test. TIA = Transient ischemic attack.

with pre-existing cognitive decrements [12]. Previous studies have shown that the use of any psychotropic drug [36] or, specifically, BZD [37-40] or BZD used concomitantly with Ops [30] is associated with cognitive decline in a non-demented aged population.

In our study, concomitant use of a BZD with an $\mathrm{AD}$, an $\mathrm{ACh}$, an $\mathrm{AP}$ or any drug with CNS effects predicted cognitive decline. This is in line with the previous finding [12] that concomitant use of a BZD and an AP is associated with precipitous cognitive decline. Only 
Table 5. Significant associations between the use of psychotropics or other drugs with CNS effects and change in cognitive functioning (MMSE) during a 7.6-year follow-up, by gender and age

\begin{tabular}{|c|c|c|c|c|c|c|c|c|c|c|c|c|}
\hline \multirow[t]{3}{*}{ Medication } & \multirow[t]{3}{*}{ Age } & \multicolumn{5}{|c|}{ Baseline MMSE } & \multicolumn{2}{|c|}{ MMSE at follow-up } & \multicolumn{4}{|c|}{ Change in MMSE } \\
\hline & & \multicolumn{2}{|c|}{ users } & \multicolumn{2}{|c|}{ controls } & \multirow[t]{2}{*}{$\mathrm{p}$} & \multicolumn{2}{|r|}{ controls } & \multirow[t]{2}{*}{ users } & \multirow[t]{2}{*}{ controls } & \multirow{2}{*}{$\begin{array}{l}\mathrm{p} \text { for } \\
\text { diff. }\end{array}$} & \multirow{2}{*}{$\begin{array}{l}\text { adjusted } \\
\mathrm{p}\end{array}$} \\
\hline & & $\mathrm{n}$ & mean $\pm S D$ & $\mathrm{n}$ & mean $\pm \mathrm{SD}$ & & mean $\pm \mathrm{SD}^{2}$ & mean $\pm \mathrm{SD}^{2}$ & & & & \\
\hline $\mathrm{BZD}^{1}$ & $75+$ & 8 & $20.9 \pm 2.8$ & 11 & $21.1 \pm 3.3$ & 0.729 & $12.3 \pm 7.6$ & $17.8 \pm 5.6$ & $-8.6 \pm 7.0$ & $-3.3 \pm 5.6$ & 0.116 & 0.015 \\
\hline $\mathrm{BZD}^{2}$ & $75+$ & 8 & $20.9 \pm 2.8$ & 22 & $17.9 \pm 7.5$ & 0.532 & $12.3 \pm 7.6$ & $15.6 \pm 8.4$ & $-8.6 \pm 7.0$ & $-2.3 \pm 5.9$ & 0.027 & 0.002 \\
\hline Any psychotropic drug ${ }^{2}$ (AP, BZD, AD) & $75+$ & 12 & $16.9 \pm 8.0$ & 18 & $19.9 \pm 5.5$ & 0.318 & $11.0 \pm 8.7$ & $17.2 \pm 7.0$ & $-5.9 \pm 7.0$ & $-2.7 \pm 6.4$ & 0.309 & 0.037 \\
\hline \multicolumn{13}{|l|}{$\mathrm{BZD}$ and } \\
\hline $\mathrm{AP}^{1}$ & $65+$ & 1 & 23 & 27 & $21.5 \pm 2.9$ & 0.415 & 7 & $20.1 \pm 7.2$ & -16 & $-1.4 \pm 7.8$ & 0.137 & 0.038 \\
\hline $\mathrm{AD}^{1}$ & $75+$ & 3 & $18.7 \pm 3.8$ & 11 & $21.1 \pm 3.3$ & 0.371 & $8.0 \pm 1.7$ & $17.8 \pm 5.6$ & $-10.7 \pm 4.7$ & $-3.2 \pm 5.6$ & 0.085 & 0.021 \\
\hline Any drug with CNS effects ${ }^{1}$ & $65+$ & 5 & $20.0 \pm 3.3$ & 27 & $21.5 \pm 2.9$ & 0.329 & $10.4 \pm 10.5$ & $20.1 \pm 7.2$ & $-9.6 \pm 9.9$ & $-1.4 \pm 7.8$ & 0.101 & 0.038 \\
\hline $\mathrm{ACh}^{1}$ & $75+$ & 2 & $18.6 \pm 3.5$ & 11 & $21.1 \pm 3.3$ & 0.184 & $3.5 \pm 4.9$ & $17.8 \pm 5.6$ & $-15.0 \pm 8.5$ & $-3.3 \pm 5.6$ & 0.059 & 0.042 \\
\hline Any drug with CNS effects ${ }^{1}$ & $75+$ & 4 & $19.3 \pm 3.3$ & 11 & $21.1 \pm 3.3$ & 0.279 & $6.0 \pm 4.4$ & $17.8 \pm 5.6$ & $-13.3 \pm 6.5$ & $-3.3 \pm 5.6$ & 0.031 & 0.003 \\
\hline Any drug with CNS effects ${ }^{2}$ & $65+$ & 5 & $20.0 \pm 3.3$ & 47 & $20.0 \pm 5.7$ & 0.603 & $10.4 \pm 10.5$ & $18.7 \pm 8.3$ & $-9.6 \pm 9.9$ & $-1.3 \pm 7.2$ & 0.064 & 0.045 \\
\hline Any drug with CNS effects ${ }^{2}$ & $75+$ & 4 & $19.3 \pm 3.3$ & 26 & $18.6 \pm 7.0$ & 0.573 & $6.0 \pm 4.4$ & $16.0 \pm 7.8$ & $-13.3 \pm 6.5$ & $-2.6 \pm 5.6$ & 0.009 & 0.001 \\
\hline
\end{tabular}

$\mathrm{p}=\mathrm{p}$ value for difference in MMSE at baseline between users and controls; $\mathrm{p}$ for diff. $=\mathrm{p}$ value for difference of change in MMSE between users and controls; adjusted $\mathrm{p}=\mathrm{p}$ value for difference of change in MMSE between users and controls adjusted for confounding variables (age). ${ }^{1}$ Control group: no medication with effects on CNS. ${ }^{2}$ Control group: non-users of corresponding medications.

one study [12] has explored the effect of concomitant use of medications having CNS effects on cognitive function in a cognitively disabled population. That study, however, had a short follow-up period (12 months) and only included patients diagnosed with Alzheimer's disease, excluding patient groups with cognitive decline caused by other disorders. Additionally, that study examined only the use of APs, BZDs and cholinergic medications in Alzheimer's disease.

It is obvious that the medications in the present study were used to treat the behavioral and psychological symptoms connected to declined cognition [1-8] in our sample. The important question is whether the precipitous cognitive decline among those patients receiving medications with CNS effects was directly caused by the medications or is the result of a more aggressive dementing disorder with more difficult behavioral and psychological symptoms of dementia requiring medical treatment. However, in this sample only one participant was diagnosed with dementia and the other diagnosed conditions were not themselves cognitively progressive. Thus, it is possible that the change in MMSE scores was directly caused by the medications. One placebo-controlled, randomized controlled trial [13] supports the idea that AP use (in this study quetiapine, an atypical AP with some anticholinergic properties) increases the risk of hastened cognitive decline among patients with Alzheimer's disease, but it did not assess this risk with the concomitant use of other drugs. Another randomized controlled trial found a risk of additional cognitive decline when Alzheimer patients with behavioral and psychological symptoms of dementia were treated with atypical APs (risperidone, quetiapine, olanzapine) compared to placebo [14]. The association between use of an ACh and cognitive decline has been previously shown in longitudinal epidemiologic studies among the aged $[25,41,42]$, but no such results have been published for a population with cognitive decline at baseline. Only tricyclic ADs and conventional APs were used in our population in the beginning of the 1990s, and the strong anticholinergic properties of these medications, combined with the CNS-depressing GABAergic properties of BZDs may have mediated the detected cognitive adverse effects.

Complete cognitive follow-up data were obtained for 52 participants. The prospective, longitudinal design of this study is a major methodological strength. A longitudinal population study such as the one we performed cannot directly show causalities, but it shows associations between certain factors and the risk of a harmful effect. Many known risk factors (excluding the use of alcohol) could be adjusted for in our study. 
Our cohort consists of an older general population with cognitive decline. The participation rates were high in both phases of the Lieto study. Medication history and clinical background data were recorded reliably. The measure of cognitive functioning (MMSE, a measure of general cognitive performance) is a frequently used, validated instrument for assessing global cognitive functioning. Only participants who had a MMSE total score of $0-23$, indicating cognitive decline at baseline, were included in the present study. The MMSE cut-off point of $24 / 23$ provides a sensitivity of $69 \%$ and a specificity of $99 \%$ for dementia [43]. Data on cognitive change were available only for individuals who were alive and participated in both phases. The difference in the number of subjects between Phase 1 and Phase 2 is accounted for by individuals who had died during the follow-up period, refused to participate, or were lost to follow-up. We adjusted the results for several known risk factors of cognitive decline, but co-existing medical or other conditions or behaviors (e.g. the use of alcohol) may also be related to cognitive decline. Alcohol use was not measured during the first phase, therefore we could not use it as a confounding variable. However, in our population only one subject had a diagnosis of excessive alcohol use. Previous studies on alcohol use among Finns have shown that it diminishes with increasing age. A previous study found only a few older individuals who were classified as frequent users and who drank large quantities of alcohol [44]. In our study, the majority of participants (13 of 15 men and 35 of 37 women) were living at home at baseline. During the follow-up, no men, but 13 of 37 women were institutionalized. We suggest that the material did not include current heavy users of alcohol.

During the early 1990s, it was rare for aged Finns to receive medications with CNS effects. The concomitant use of several drugs with CNS effects was even rarer. These facts influence the power of the statistical tests, especially in analyzing the data adjusted for gender and age. Drug use categories were determined by the data from the first phase of the study. Additional drugs may have been started and previous ones may have been discontinued during the follow-up. However, many of these kinds of drugs are prescribed on a long-term basis, for many years among the aged in Finland, even against recommendations (e.g. BZD) [45]. The great majority of medications in the study population were used on a long-term basis.

No cholinergic medication for Alzheimer's disease was approved for marketing during the study period, and therefore, this category could not be analyzed. Only conventional APs were available in the beginning of the 1990s; thus, differences between conventional and atypical APs could not be studied either. Tricyclic ADs were the only class of ADs used, meaning that no comparison between tricyclic ADs and newer ADs (e.g. SSRI) was possible.

The number of individuals using two or more medications with CNS effects concomitantly was low. This poses statistical limitations. Negative results may be caused by the rather small sample size and the small number of users. Due to a lack of statistical power, the results do not prove that medications with CNS effects have a negative effect on cognition. Positive results, especially measured by the quite insensitive MMSE, however, show strong associations in this population. Based on the results from the present study, prescribing two or more medications with CNS effects to cognitively disabled older individuals should be based on a critical, individualized assessment. The cognitively disabled requiring treatment with multiple psychotropics should be carefully monitored to permit earlier detection of the precipitous cognitive decline associated with the use of these medications.

\section{Conclusions}

The use of a BZD or any psychotropic medication may be an independent risk factor for further cognitive decline in the cognitively disabled aged. The concomitant use of a BZD and an $\mathrm{AP}$, an $\mathrm{AD}$, an $\mathrm{ACh}$ or any CNS-affecting medication poses a higher risk of precipitous 
cognitive decline. However, studies with larger sample sizes and studies on possible pathophysiologic mechanisms are needed to develop a more complete understanding of these phenomena.

\section{Acknowledgements}

The authors would like to thank Health Centre physician Dr. Minna Löppönen, MD, $\mathrm{PhD}$, for her substantial contribution in collecting data in the second phase of the study, ADP Designers Jukka Saukkoriipi and Teemu Kemppainen for their valuable work in performing the statistical analyses, and Project Secretary Selena Nitecki for her assistance in the writing process.

\section{Disclosure Statement}

This study was financially supported by the 19th February Fund of the Finnish Heart Association; the Finnish Academy; the Federation of Municipalities of Härkätie, Lieto, Finland; Turku University Hospital Grant EVO; Satakunta Hospital District Grant EVO; the Finnish Association for General Practice; the Uulo Arhio Foundation; and the Finnish Cultural Foundation.

J.P. has lectured in continuing education courses for physicians, nurses and physiotherapists sponsored by Janssen-Cilag, Lundbeck and Novartis. J.N., T.V. and R.I. have no competing interests. I.R. has given lectures in continuing education courses for physicians and nurses sponsored by Novartis and Janssen-Cilag. S.-L.K. has given lectures in continuing education courses for physicians, nurses and physiotherapists sponsored by Janssen-Cilag, Pfizer, Lundbeck, Novartis, Leiras and ratiopharm.

All authors of the article are independent from funders and have no conflicts of interest. The financial sponsors played no role in the design, execution, analysis or interpretation of data or in preparing the manuscript.

\section{References}

-1 Wragg RE, Jeste DV: Neuroleptics and alternative treatments. Management of behavioral symptoms and psychosis in Alzheimer's disease and related conditions. Psychiatr Clin North Am 1988;11:195213.

-2 Semla TP, Cohen D, Freels S, Paveza GJ, Ashford JW, Gorelick P, Luchins D, Eisdorfer C: Psychotropic drug use in relation to psychiatric symptoms in community-living persons with Alzheimer's disease. Pharmacotherapy 1995; 15:495-501.

-3 Burke WJ, Dewan V, Wengel SP, Roccaforte WH, Nadolny GC, Folks DG: The use of selective serotonin reuptake inhibitors for depression and psychosis complicating dementia. Int J Geriatr Psychiatry 1997;12:519-525.

-4 Stern RG, Duffelmeyer ME, Zemishlani Z, Davidson M: The use of benzodiazepines in the management of behavioral symptoms in demented patients. Psychiatr Clin North Am 1991;14:375-384.

-5 Lemke MR: Effect of carbamazepine on agitation in Alzheimer's inpatients refractory to neuroleptics. J Clin Psychiatry 1995;56:354-357.

-6 Tariot PN, Erb R, Podgorski CA, Cox C, Patel S, Jakimovich L, Irvine C: Efficacy and tolerability of carbamazepine for agitation and aggression in dementia. Am J Psychiatry 1998;155:54-61.

-7 Porsteinsson AP, Tariot PN, Erb R, Gaile S: An open trial of valproate for agitation in geriatric neuropsychiatric disorders. Am J Geriatr Psychiatry 1997;5:344-351. 
-8 Finkel SI, Costa e Silva J, Cohen G, Miller S, Sartorius N: Behavioral and psychological signs and symptoms of dementia: a consensus statement on current knowledge and implications for research and treatment. Int Psychogeriatr 1996;8(suppl 3):497-500.

-9 Jeste DV, Caligiuri MP, Paulsen JS, Heaton RK, Lacro JP, Harris MJ, Bailey A, Fell RL, McAdams LA: Risk of tardive dyskinesia in older patients. A prospective longitudinal study of 266 outpatients. Arch Gen Psychiatry 1995;52:756-765.

-10 Sultzer DL, Davis SM, Tariot PN, Dagerman KS, Lebowitz BD, Lyketsos CG, Rosenheck RA, Hsiao JK, Lieberman JA, Schneider LS: Clinical symptom responses to atypical antipsychotic medications in Alzheimer's disease: phase 1 outcomes from the CATIE-AD effectiveness trial. Am J Psychiatry 2008; $165: 844-854$.

-11 McShane R, Keene J, Gedling K, Fairburn C, Jacoby R, Hope T: Do neuroleptic drugs hasten cognitive decline in dementia? Prospective study with necropsy follow up. BMJ 1997;314:266-270.

-12 Ellul J, Archer N, Foy CM, Poppe M, Boothby H, Nicholas H, Brown RG, Lovestone S: The effects of commonly prescribed drugs in patients with Alzheimer's disease on the rate of deterioration. J Neurol Neurosurg Psychiatry 2007;78:233-239.

- 13 Ballard C, Margallo-Lana M, Juszczak E, Douglas S, Swann A, Thomas A, O’Brien J, Everratt A, Sadler S, Maddison C, Lee L, Bannister C, Elvish R, Jacoby R: Quetiapine and rivastigmine and cognitive decline in Alzheimer's disease: randomised double blind placebo controlled trial. BMJ 2005; 330:874.

-14 Vigen CL, Mack WJ, Keefe RS, Sano M, Sultzer DL, Stroup TS, Dagerman KS, Hsiao JK, Lebowitz BD, Lyketsos CG, Tariot PN, Zheng L, Schneider LS: Cognitive effects of atypical antipsychotic medications in patients with Alzheimer's disease: outcomes from CATIE-AD. Am J Psychiatry 2011;168: 831-839.

-15 Livingston G, Walker AE, Katona CL, Cooper C: Antipsychotics and cognitive decline in Alzheimer's disease: The LASER-Alzheimer's disease longitudinal study. J Neurol Neurosurg Psychiatry 2007;78: $25-29$.

-16 Lopez OL, Wisniewski SR, Becker JT, Boller F, DeKosky ST: Psychiatric medication and abnormal behavior as predictors of progression in probable Alzheimer disease. Arch Neurol 1999;56:12661272.

17 Rocca P, Marino F, Montemagni C, Perrone D, Bogetto F: Risperidone, olanzapine and quetiapine in the treatment of behavioral and psychological symptoms in patients with Alzheimer's disease: preliminary findings from a naturalistic, retrospective study. Psychiatry Clin Neurosci 2007;61:622-629.

18 Caballero J, Hitchcock M, Scharre D, Beversdorf D, Nahata MC: Cognitive effects of atypical antipsychotics in patients with Alzheimer's disease and comorbid psychiatric or behavioral problems: a retrospective study. Clin Ther 2006;28:1695-1700.

-19 Rainer MK, Masching AJ, Ertl MG, Kraxberger E, Haushofer M: Effect of risperidone on behavioral and psychological symptoms and cognitive function in dementia. J Clin Psychiatry 2001;62:894-900.

-20 Rainer M, Haushofer M, Pfolz H, Struhal C, Wick W: Quetiapine versus risperidone in elderly patients with behavioural and psychological symptoms of dementia: efficacy, safety and cognitive function. Eur Psychiatry 2007;22:395-403.

-21 De Deyn PP, Katz IR, Brodaty H, Lyons B, Greenspan A, Burns A: Management of agitation, aggression, and psychosis associated with dementia: a pooled analysis including three randomized, placebo-controlled double-blind trials in nursing home residents treated with risperidone. Clin Neurol Neurosurg 2005;107:497-508.

-22 Oxman TE: Antidepressants and cognitive impairment in the elderly. J Clin Psychiatry 1996;57(suppl 5):38-44.

-23 Jessen F, Kaduszkiewicz H, Daerr M, Bickel H, Pentzek M, Riedel-Heller S, Wagner M, Weyerer S, Wiese B, van den Bussche H, Broich K, Maier W: Anticholinergic drug use and risk for dementia: target for dementia prevention. Eur Arch Psychiatry Clin Neurosci 2010;260(suppl 2):S111-S115.

- 24 Sittironnarit G, Ames D, Bush AI, Faux N, Flicker L, Foster J, Hilmer S, Lautenschlager NT, Maruff P, Masters CL, Martins RN, Rowe C, Szoeke C, Ellis KA: Effects of anticholinergic drugs on cognitive function in older Australians: results from the AIBL study. Dement Geriatr Cogn Disord 2011; 31:173-178.

-25 Ancelin ML, Artero S, Portet F, Dupuy AM, Touchon J, Ritchie K: Non-degenerative mild cognitive impairment in elderly people and use of anticholinergic drugs: longitudinal cohort study. BMJ 2006; 332:455-459. 
-26 Konovalov S, Muralee S, Tampi RR: Anticonvulsants for the treatment of behavioral and psychological symptoms of dementia: a literature review. Int Psychogeriatr 2008;20:293-308.

-27 Lorenz KA, Lynn J, Dy SM, Shugarman LR, Wilkinson A, Mularski RA, Morton SC, Hughes RG, Hilton LK, Maglione M, Rhodes SL, Rolon C, Sun VC, Shekelle PG: Evidence for improving palliative care at the end of life: a systematic review. Ann Intern Med 2008;148:147-159.

-28 Hartikainen S, Mantyselka P, Louhivuori-Laako K, Enlund H, Sulkava R: Concomitant use of analgesics and psychotropics in home-dwelling elderly people-kuopio $75+$ study. Br J Clin Pharmacol 2005;60:306-310.

-29 Pitkala KH, Laurila JV, Strandberg TE, Tilvis RS: Behavioral symptoms and the administration of psychotropic drugs to aged patients with dementia in nursing homes and in acute geriatric wards. Int Psychogeriatr 2004;16:61-74.

-30 Puustinen J, Nurminen J, Lopponen M, Vahlberg T, Isoaho R, Raiha I, Kivela SL: Use of CNS medications and cognitive decline in the aged: a longitudinal population-based study. BMC Geriatr 2011; 11:70.

-31 Isoaho R, Puolijoki H, Huhti E, Kivela SL, Tala E: Prevalence of asthma in elderly Finns. J Clin Epidemiol 1994;47:1109-1118.

-32 Lopponen M, Raiha I, Isoaho R, Vahlberg T, Kivela SL: Diagnosing cognitive impairment and dementia in primary health care - a more active approach is needed. Age Ageing 2003;32:606-612.

-33 Salmon DP, Riekkinen PJ, Katzman R, Zhang MY, Jin H, Yu E: Cross-cultural studies of dementia. A comparison of mini-mental state examination performance in Finland and China. Arch Neurol 1989;46:769-772.

-34 Folstein MF, Folstein SE, McHugh PR: 'Mini-mental state'. A practical method for grading the cognitive state of patients for the clinician. J Psychiatr Res 1975;12:189-198.

35 Classification of Medicines (ATC) and Defined Daily Doses (DDD). Helsinki, Finland, National Agency of Medicines, 1991.

-36 Berg S, Dellasega C: The use of psychoactive medications and cognitive function in older adults. J Aging Health 1996;8:136-149.

-37 Hanlon JT, Horner RD, Schmader KE, Fillenbaum GG, Lewis IK, Wall WE Jr, Landerman LR, Pieper CF, Blazer DG, Cohen HJ: Benzodiazepine use and cognitive function among community-dwelling elderly. Clin Pharmacol Ther 1998;64:684-692.

-38 Lagnaoui R, Begaud B, Moore N, Chaslerie A, Fourrier A, Letenneur L, Dartigues JF, Moride Y: Benzodiazepine use and risk of dementia: a nested case-control study. J Clin Epidemiol 2002;55:314-318.

-39 Paterniti S, Dufouil C, Alperovitch A: Long-term benzodiazepine use and cognitive decline in the elderly: the epidemiology of vascular aging study. J Clin Psychopharmacol 2002;22:285-293.

-40 Bierman EJ, Comijs HC, Gundy CM, Sonnenberg C, Jonker C, Beekman AT: The effect of chronic benzodiazepine use on cognitive functioning in older persons: good, bad or indifferent? Int J Geriatr Psychiatry 2007;22:1194-1200.

-41 Bottiggi KA, Salazar JC, Yu L, Caban-Holt AM, Ryan M, Mendiondo MS, Schmitt FA: Long-term cognitive impact of anticholinergic medications in older adults. Am J Geriatr Psychiatry 2006;14: 980-984.

-42 Knegtering H, Eijck M, Huijsman A: Effects of antidepressants on cognitive functioning of elderly patients. A review. Drugs Aging 1994;5:192-199.

-43 Tangalos EG, Smith GE, Ivnik RJ, Petersen RC, Kokmen E, Kurland LT, Offord KP, Parisi JE: The mini-mental state examination in general medical practice: clinical utility and acceptance. Mayo Clin Proc 1996;71:829-837.

-44 Kivela SL, Nissinen A, Ketola A, Punsar S, Puska P, Karvonen M: Changes in alcohol consumption during a ten-year follow-up among Finnish men aged 55-74 years. Funct Neurol 1988;3:167-178.

$\checkmark 45$ Puustinen J, Nurminen J, Kukola M, Vahlberg T, Laine K, Kivela SL: Associations between use of benzodiazepines or related drugs and health, physical abilities and cognitive function: a non-randomised clinical study in the elderly. Drugs Aging 2007;24:1045-1059. 